\title{
Pensar o neutro e seu silêncio: esta radicalidade em potência
}

Helano Jader Ribeiro

UFPel

\section{Resumo}

O objetivo deste artigo é analisar o conceito ou arquiconceito de neutro a partir de Roland Barthes e Maurice Blanchot. Que figura indecidível é essa que corta e divide a escritura? Se pensarmos nessa fuga tácita dos binômios, nessa escritura branca como uma figura lisa, que consegue se deslizar [correr pelo rio da linguagem] pelo fechamento existente em masculino e feminino, podemos conceber o neutro, acima de tudo, como uma possibilidade política de ética do in-visível e do in-au-dito. E se a literatura tende para o silêncio, segundo Blanchot, é porque ela mesma se movimenta na direção dos seus limites. Esse limite, esse neutro, é a terceira margem, é a borda de um estranho limbo, o entre-lugar que chamamos de escritura.

Palavras-chave: Roland Barthes; Maurice Blanchot; neutro.

\begin{abstract}
The intention of this paper is to analyze the concept or arquiconcept neutral from Roland Barthes and Maurice Blanchot. What is this undecidable figure that cuts and splits the writing? If we think in these tacit trail of dichotomies, such as a plain white writing figure, which manages to slip [run through the river of language] through existing lock into male and female, can conceive neutral, above all as a political possibility of ethics the in-visible and un-told. And if literature tends to silence, according to Blanchot, it is because it moves itself toward its limits. This limit, this neutral is the third blank, is the edge of a strange limbo between-place that we call writing.
\end{abstract}

Keywords: Roland Barthes; Maurice Blanchot; neutral. 
1. BARTHES, Roland.

"Masculino, feminino, neutro", 2004, p. 245.
BARTHES [silêncio]

A gramática aponta, através do elemento neutro, para aqueles vocábulos que não apresentam características nem masculinas, nem femininas, transitando, pois, no limbo da indecidibilidade: ne-uter [nem um nem outro, um e outro]. De 18 de fevereiro a 3 de junho de 1978, Roland Barthes ministra no Collège de France seu curso sobre o Neutro. Segundo ele o Neutro não pode ser definido, mas sim ensaiado, deve ser visto antes dentro da abertura de uma performance do que da simples representação daquilo que não se deixa fechar por masculino e feminino:

Situar simbolicamente o castrato na estrutura institucional dos sexos, que é inelutavelmente binária; pois, se nos ativermos a essa estrutura, uma vez que a ausência de marca constitui o feminino, de que poderia ser feito o neutro? $\mathrm{Na}$ realidade - e a lingüística o comprova -, o neutro não pode ser tomado diretamente numa estrutura sexual [...]. ${ }^{1}$

Assim, o Neutro surge rasgado de possibilidades figurativas que revelam a disseminação ou alucinação de sentidos, ou seja, ele se apresenta em sua inaparição, oferecendo nesse silêncio o in-au-dito pelo visto, dentro do imperceptível de suas formas. Este seria, então, um conceito burláo, sonso, que desarma a empáfia da verdade do discurso.

$\mathrm{O}$ procedimento de Barthes consiste no exame de vinte e três figuras que ele irá chamar de traços, cintilaçōes, essas figuras formariam um gesto que tocasse o Neutro. Dentre essas 23 figuras, podemos encontrar: o silêncio, a delicadeza, o sono, a fadiga e a cor [ou, sua falta: o incolor], entre outros. Um dos grandes objetivos do curso é fazer, então, que o Neutro cintile, de modo que, Barthes irá escolher como repertório de suas aulas textos com os quais tem grande afinidade. Juntos permanecem nesse repertoire Blanchot e John Cage, Deleuze e Lacan, Pascal e Baudelaire, Pírron e Joseph de Maistre.

Barthes n'O grau zero da escritura, de 1953, já apontava para o Neutro [grafado com inicial em maiúscula, para ressaltar seu caráter conceitual] como uma espécie de escritura indiferente, branca, que foge à linguagem literária, e esta escritura escapa assim de uma sujeição ordenada pela mesma linguagem literária. Ele assinala que, entre dois termos de um binômio, existe um terceiro elemento: o termo Neutro. No livro Roland Barthes por Roland Barthes escreve:

Figuras do Neutro: a escritura branca, isenta de todo teatro literário - a linguagem adâmica - a insignificância deleitável - o liso - o vazio, o inconsútil - a Prosa (categoria política descrita por Michelet) - a discrição - a vacância da "pessoa", 
se não anulada, pelo menos tornada ilocalizável - a ausência de imago - a suspensão de julgamento, de processo - o deslocamento - a recusa de "assumir uma compostura" (a recusa de toda compostura) - o princípio da delicadeza - a deriva - o gozo: tudo o que esquiva, desmonta ou torna irrisórios a exibição, o domínio, a intimidação. ${ }^{2}$

A recusa de assumir uma compostura, analisado no trecho de Barthes, pode ser lido como potência. O conceito de potência ocupa um extenso lugar na filosofia ocidental. A partir de Aristóteles circula como peça central de seu pensamento. Ele diz que o arquiteto tem a potência de construir mesmo quando não está construindo, ou que o tocador de lira tem a potência de tocar mesmo quando não toca:

Potência significa [a] o princípio do movimento ou da mudança existente em alguma coisa distinta da coisa mudada, ou nela enquanto outra. Por exemplo, a arte da construçáo é uma potencia enquanto está ausente na coisa construída. Mas a arte da medicina, a qual é uma potência, pode estar presente no paciente, ainda que não enquanto paciente. Desta maneira, [entende-se que] potência significa o princípio em geral da mudança ou movimento numa outra coisa, ou na mesma coisa enquanto outra; ou o princípio do ser de uma coisa movida, transformada por uma outra coisa, ou por si mesma enquanto outra $[\ldots]]^{3}$

Ou seja, a potência é definida essencialmente pela possibilidade do seu não-exercício. $\mathrm{O}$ arquiteto é potente enquanto pode não-construir, e o tocador de lira assim o é por não-tocar seu instrumento. Giorgio Agamben, ao analisar o conceito de potência em Aristóteles, em seu livro Bartleby Escrita da potência diz:

A mente é, então, não uma coisa, mas um ser de pura potência e a imagem da tabuinha de escrever, sobre a qual nada está ainda escrito, serve precisamente para representar o modo de ser uma pura potência. Toda a potência de ser ou de fazer qualquer coisa é, de facto, para Aristóteles, sempre também potência de náo ser ou de não fazer [...]. Essa "potência de náo" é o segredo cardeal da doutrina aristotélica sobre a potência, que faz de toda potência, por si mesma, uma impotência. ${ }^{4}$

Agamben procura um confronto minucioso com as ambiguidades teóricas relativas a uma teoria da potência. Ele nos apresenta o questionamento a respeito da própria vida como potência que se ultrapassa e se supera incessantemente: "Crer que a vontade tenha poder sobre a potência, que a passagem ao acto seja o resultado de uma decisão que póe fim à ambiguidade da potência (que é sempre potência de fazer e não de fazer - esta é a perpétua ilusão da moral)." ${ }^{5}$ Agamben pensa a potência não ape-
2. Idem. Roland Barthes por Roland Barthes, 2003, p. 149. Grifo meu.

3. ARISTÓTELES. Metafísica, 2012, p. 149.

4. AGAMBEN, Giorgio.

'Bartleby ou da contingência", 2007, p. 13.

5. Ibidem, p. 26. 
6. DELEUZE, Gilles. Crítica e clinica, 1997, p. 85.

7. AGAMBEN, Giorgio.

A potência do pensamento, 2015 , p. 249.

8. ROSA, João Guimarães.

"A Terceira margem do rio", 2001, p. 81.

9. Ibidem, p. 80 . nas em torno da ação que a realiza e esvazia, mas também como potência de não, potência de não executar ou pensar algo, pela qual se apresenta a tabuinha vazia não apenas como um momento anterior à escrita, mas como sua descoberta ulterior, ou seja, trata-se de um exercício que implica também numa ética.

Acho melhor não - no original, "I would prefer not to" - de Bartleby, o personagem de Herman Melville do conto "Bartlebly, o escrivão", surge como exemplo do desarticular do outro através do não-pensamento, através do que Gilles Deleuze chama em Crítica e clínica de fórmula:

A fórmula I WOULD PREFER NOT TO exclui qualquer alternativa e engole o que pretende conservar assim como descarta qualquer outra coisa; implica que Bartleby pára de copiar, isto é, de reproduzir palavras; cava uma zona de indeterminação que faz com que as palavras já não se distingam, produz o vazio da linguagem. Mas também desarticula todo ato de fala, ao mesmo tempo que faz de Bartleby um puro excluído, ao qual já nenhuma situação social pode ser atribuída. ${ }^{6}$

Se o calar-se do personagem Bartleby de Herman Melville é potência enquanto silêncio é porque esse mesmo silêncio é o que legitima e assegura sua singularidade em sua comunidade de enfrentamento. À potência pertence também sua própria impotência e ter essa faculdade significa, também, ter uma privação [o escuro, o silêncio]. Toda ambiguidade relativa à potência humana, possui uma relação com sua privação, ou como sugere Agamben: " [...] é sempre - e em relação à mesma coisa - potência de ser e de não ser, de fazer e de não fazer. É essa relação que constitui, para Aristóteles, a essência da potência."7

O mesmo pode ser dito acerca do conto de Guimarães Rosa "A terceira margem do rio". Essa terceira margem é de ordenação outra, ou um espaço nonada, em que o silêncio se manifesta, se materializa em forma de estranhamento, ou melhor, escritura, a terceira margem é da natureza do neutro: "Nosso pai não voltou, ele não tinha ido a nenhuma parte." ${ }^{3}$ á um dito pelo não-dito que é aprisionado na voz do pai. Ao filho, o narrador, cabe dizer: "Sem alegria nem cuidado, nosso pai encalcou o chapéu e decidiu um adeus para a gente. Nem falou outras palavras [...]"9. A resistência inoperante desse mesmo pai é potência de fazer ao não fazer, de falar ou de calar, seu alvo não é o da rebeldia despropositada, mas a escolha de uma vida que consiste em não escolher. $\mathrm{O}$ silêncio como potência pressupóe uma ética que inopera a lei, visto que ele é esse sem-lei escorregadio que não pode ser captado/cooptado, ou seja, ele impede a sujeição:

Podemos retornar das lonjuras etimológicas ou descer das alturas místicas sem perder o paradigma sileoltaceo; como 
todos sabem, a fala, o exercício da fala, está ligada ao problema do poder: é o tema do direito à palavra. Havia em grego (porque nas instituiçôes) uma palavra para esse direito legal: isegoria: direito para todos de falar em assembleia. Problema que continua em cena: a revindicação da palavra, a supressão do direito de expressão. Mas atrás da cena, ou no fundo, de lado, outra demanda procura fazer-se ouvir (mas como?): o direito do silêncio [...] Direito de calar-se, direito de não ouvir [...] o que toma a forma de uma revindicação coletiva, quase político-, é o direito à tranquilidade $\mathrm{da}$ natureza, o direito ao silere, náo o direito ao tacere $[. . .]^{10}$

O exílio desse pai mudo se dá em uma terceira margem do rio [dando-lhe o direito à natureza], margem essa que se localiza na linha do intangível, incaptável, do neutro. A inoperância através do silêncio é de penetração, mostra as lacunas de uma linguagem que se revela repleta de fissuras. $\mathrm{O}$ vazio, então, abre espaço para a suspensão do tempo nessa terceira margem: "Os tempos mudavam, no devagar depressa dos tempos."11

O que nos leva a dizer que o Neutro é potência que não se encerra em si mesma, nele reside o poder-dizer, mas que não é dito [silêncio]. Ele se revela na possibilidade da escritura de não executar, de fugir de uma escolha, ou melhor, de adotar uma não-escolha que é da ordem do indecidível. É não aniquilar, através de uma só decisão, todas as possibilidades possíveis.

Roland Barthes nos fala, ainda, que a escritura é o grau zero que esvazia toda identidade [iniciando-se pelo corpo que escreve] de modo que ela se torna independente desse mesmo sujeito que escreve, ou seja, do autor. A escritura impóe o fim de toda a voz e origem: esta é esvaziada por aquele e o que entra em seu lugar é a escritura, que coloca em discussão a existência de toda e qualquer origem:

Na novela Sarrasine, falando de um castrado disfarçado em mulher, Balzac escreve esta frase: "Era a mulher, com seus medos repentinos, seus caprichos sem razáo, suas perturbaçôes instintivas, suas audácias sem causa, suas bravatas e sua deliciosa finura de sentimentos". Quem fala assim? É o herói da novela, interessado em ignorar o castrado que se esconde sob a mulher? É o indivíduo Balzac, dotado, por sua experiência pessoal, de uma filosofia da mulher? É o autor Balzac, professando idéias "literárias" sobre a mulher? É a sabedoria universal? A psicologia romântica? Jamais será possível saber, pela simples razão que a escritura é a destruição de toda voz, de toda origem. A escritura é esse neutro [grifo meu], esse composto, esse oblíquo aonde foge o nosso sujeito, o branco-e-preto onde vem se perder toda identidade, a começar pela do corpo que escreve. ${ }^{12}$

Essa formulação barthesiana de grau zero da escritura já é uma reflexão primeva do conceito de Neutro, assim como bem
10. BARTHES, Roland. O neutro: anotações de aulas e seminários ministrados no Collège de France, 2003, p. 51.

11. Idem. p. 83.

12. BARTHES, Roland. "A morte do autor", 1988, p. 65. 
13. MOT'TA, Leda Tenório da. Roland Barthes - uma biografia intelectual, 2011, p. 113.

14. BARTHES, Roland. O neutro: anotações de aulas e seminários ministrados no Collège de France, 1977, 1978, 2003, p. 64.

15. BLANCHOT, Maurice. La escritura del desastre, 1990, p. 50. o percebe Leda Tenório da Motta, visto que: "Barthes confunde expressamente uma coisa e outra"13 $\mathrm{O}$ Neutro representa dentro do pensamento de Barthes essa utopia da linguagem que, constantemente, está apontando para sua indiferença e a suspensão do seu sentido, podemos, deste modo, falar de uma estética do vazio, de esvaziamento do signo. E se a escritura, ela mesma, é a destruição de toda voz, como escreve Barthes, ela é, também, uma máquina de fazer silenciar:

Notem sempre a mesma aporia do Neutro: para levar a conhecer, para apresentar, por mais ligeiramente que seja, $o$ não-falar, é preciso em certo momento falá-lo. Neutro = Impossível: falá-lo é desfazê-lo, mas não o falar é perder sua "constituição". ${ }^{14}$

Se pensarmos ainda em um dos temas que envolvem o curso de Barthes em torno do Neutro, vemos que o silêncio é uma delicadeza singular que somente se revela na impossibilidade de sua aparição. A delicadeza reside nessa recusa de deixar-se impor a fala ou de dar poder àquele que é um dos mais cruéis dos dispositivos: a linguagem [cruel, porque nos obriga a falar].

Assim, concluímos que o Neutro barthesiano, este conceito de esquiva, é potência que opera eticamente e repleto de silêncio. O neutro não se opõe a nada, porque não escolhe, mas se revela rizomaticamente em um plano de imanência que serve de palco para o jogo, um jogo produtor de derivas. Barthes, desta forma, busca muito mais que uma definiçáo do inominável Neutro, sua preocupação se baseia antes na identificação do Neutro com a própria escritura.

\section{BLANCHOT [silêncio]}

Barthes invoca com frequência Maurice Blanchot e seu conceito de neutro. $\mathrm{O}$ neutro blanchotiano não se revela somente na negação, nem afirmação, mas [e da mesma forma do conceito barthesiano] também se mostra como um conceito de potência, visto que abdica das possibilidades de escolha. $\mathrm{O}$ neutro, nesse sentido, teria a potência de tudo negar, mas prefere não fazê-lo, no entanto também se nega a tudo afirmar. Essa indecidibilidade é da ordem da desgraça, da catástrofe, do desastre: "o desastre não faz o pensamento desaparecer, mas, do pensamento, dúvidas e problemas, afirmação e negação, o silêncio e palavra, marca e insígnia." ${ }^{15} \mathrm{O}$ desastre ou neutro não podem ser considerados estritamente um conceito, o que quer dizer que não existe para o neutro, qualquer conjunto de características que o determine 
suficientemente a ponto de se chegar a uma definição, mas é um arquiconceito que se define a partir de outros conceitos.

Segundo Blanchot, a narrativa é da ordem do neutro. Se por um lado ela nada acrescenta, porque é incapaz de dizer [assim sendo, é incapaz de se ouvir], de outro se mantém suspensa no fora, que se mostra como o próprio segredo da linguagem na escritura. Mas é daí que emanam as contradições típicas do pensamento de Maurice Blanchot: essa fala do neutro nem apresenta, nem vela. $\mathrm{O}$ que náo pode ser entendido como falta de sentido. É neste ponto que reside a potência da linguagem enquanto paradoxo de si mesma, no momento em que, ao mesmo tempo, aclara obscurecendo, faz-se compreender através do mal-entendido. De acordo com Blanchot:

Noutros termos, toda linguagem começa por enunciar, e, ao enunciar, afirma. Mas poderia ser que narrar (escrever) seja atrair a linguagem a uma possibilidade de dizer que diria sem dizer o ser e sem tampouco negá-lo - ou ainda, mais claramente, estabelecer alhures o centro de gravidade da fala, lá onde falar não seria afirmar o ser e tampouco ter necessidade da negação para suspender a obra do ser, a que se perpetra ordinariamente em toda forma de expressáo. ${ }^{16}$

A negação do poder de enunciação só pode se dar, desta forma, através da voz narrativa como performance [estrategicamente]. Deste modo, o neutro insere-se em uma poética de criaçáo puramente teatral de apresentação [e náo representação]. Essa voz age, entáo, como a via crucis desse corpo da poética do neutro, formulando gestos repletos de aporias, formando uma teatralidade do dúbio, do vazio, o que nos leva à escolha forçada pelas contradiçôes, caindo nas armadilhas indecidíveis.

A voz narrativa é uma voz neutra, ela opera numa espécie de não-lugar em que a obra se silencia. Mas cabe aqui a pergunta: quem é o responsável pela narração? O ele da narração, a terceira pessoa, não é um simples substituto do sujeito, uma impessoalidade, é através desse ele em que se pronuncia o neutro. Na verdade, ele é a destituição de todo sujeito, impossibilitando, desta forma, toda objetividade, o ele não se contenta em simplesmente ocupar um espaço que, em geral, pertence ao sujeito. O ele é esse anomos, fora da lei, aquele que desliza pelos discursos autoritários e que não pode ser apreendido por eles. Trata-se aqui de uma ética política ou de uma política eticamente esboçada através do pensamento de Maurice Blanchot, visto que ele irá abrir espaço para as multiplicidades, e essa pluralidade transita numa zona de indecidibilidade vazia, mas cheia de perigo.

Pensar no sujeito, então, é pensar em um $e u$, se imaginarmos que, ao dizer $e u$, o homem estaria se pronunciando, se afirmando pela fala e este mesmo eu não deve ser dissociado de um
16. BLANCHOT, Maurice. A conversa infinita 3: a ausência do livro, o neutro o fragmentário, 2010 , p. 151. 
17. Ibidem, p. 142.

18. Ibidem, p. 148.

19. Ibidem, p. 30 .

20. Ibidem.

21. Ibidem. discurso de autoridade e verdade, ou uma tentativa de objetivar o mundo. Uma vez permeada pelas contradiçóes ambíguas, a literatura rejeita este mesmo discurso autoritário de um eu-suposto-saber:

Com frequência, numa narrativa ruim - admitindo-se que exista, o que não é de todo certo -, tem-se a impressão de que alguém fala por detrás e sopra aos personagens ou então aos acontecimentos aquilo que devem dizer: intrusão discreta e desajeitada; é, diz-se, o autor quem fala, um "eu" autoritário, ainda ancorado à vida e irrompendo imoderadamente. ${ }^{17}$

Ao renunciar esse mesmo eu autoritário o escritor torna-se, então, refém desta obra inacabada, deste livro por vir, ela devém segredo e des-orientação: "E a narrativa não seria nada mais do que uma alusão ao desvio inicial que carrega a escrita, que a desvia e que faz com que, escrevendo, entreguemo-nos a um perpétuo desviar-se."18

A literatura, assim, é espaço de um propósito sem finalidade, mas que, ainda assim apresenta a possibilidade de sua morte como limite. Ela percorre, então, um caminho que se estende até essa mesma finalidade, ou um gesto crítico que, segundo Blanchot, pode ser entendido como neutro.

O neutro, deste modo, pode ser também pensado pela/na morte ou aquilo que é desconhecido visto que: "O desconhecido é sempre pensado no neutro. O pensamento do neutro é uma ameaça e um escândalo para o pensamento." ${ }^{19}$ Porque esse desconhecido: "é verbalmente o neutro." ${ }^{20} \mathrm{E}$ continua Blanchot:

Aquilo que pertence ao neutro não é um terceiro gênero oposto aos dois outros e constituindo uma classe determinada de existentes ou de seres de razão. O neutro é aquilo que não se distribui em nenhum gênero: o não geral, o não genérico, assim como o não particular. Ele recusa a pertença tanto à categoria do objeto quanto à do sujeito. ${ }^{21}$

O neutro se move nem em direção a um, nem ao outro [nem - outro], nem-nem. Ele marca, assim, a fuga do sentido da escritura, que chegaria a uma espécie de flutuação em que o sentido é de difícil, senáo impossível, captação absoluta. O neutro, ainda, questiona, não como entendemos comumente, através de interrogaçôes, mas ele antecipa todas as respostas, é uma potência outra que leva a diferença à indiferença [literatura]. O neutro blanchotiano também se revela em sua mobilidade, é um deslizamento rizomático, produtor de derivas sem norte, sem aportes ou amarras às margens:

Mas um dos traços do neutro [...] é, furtando-se à afirmação como à negação, de encerrar, ainda, sem a forma, não 
de uma resposta, mas de um recuo diante de tudo aquilo que viria, nessa resposta, responder. $\mathrm{O}$ neutro questiona: ele não questiona à maneira comum, interrogando; embora pareça não reter nada da atenção que lhe dirigida, embora se deixe ele próprio atravessar, neutralizando-a, por toda força interrogativa, ele leva sempre mais adiante o limite em que esta ainda se exerceria, quando o próprio signo do questionamento, apagando-se, não deixa mais à afirmação o direito, o poder de responder. ${ }^{22}$

Esse desconhecido mencionado por Blanchot não deve ser pensado pelo objeto, tampouco pelo sujeito. Ao desconhecido não cabe a revelação, mas sim sua indicação, a busca dessa mesma revelação. Assim, podemos pensar a busca e a poesia como cúmplices que revelam o desconhecido, mas que ainda o mantém encoberto, velado:: "Essa relação deve deixar intacto intocado - o que transmite e náo desvelado o que descobre" 23 O desconhecido no pensamento do neutro foge à escolha, assim como à negação. Ele surge de outra parte, de outra margem, não pode ser apreendido em nenhum horizonte representável, captável, é, pois, do lugar do invisível. Nesse sentido, a poesia deve manter-se em seu silêncio. Apreendê-la ou compreendê-la objetivamente seria da ordem do bárbaro. Assim, surge o escritor, ou aquele que é capaz de impor o silêncio à fala de nome escritura:

Um escritor é aquele que impóe o silêncio a essa fala [infinita, que é a escritura], e uma obra literária é, para aquele que sabe penetrar nela, uma preciosa morada de silêncio, uma defesa firme e uma alta muralha contra essa imensidade falante que se dirige a nós, desviando-nos de nós. ${ }^{24}$

Na palavra, existe, pois, uma profusão de ausência. Ao falarmos substituímos presença por ausência, ou melhor, silêncio. O silêncio surge, então, como essa forma paroxística da ausência. Somos levados a concluir que o silêncio reside na própria palavra, em potência. Nesse vácuo, nessa brancura vazia, nasce o pensamento de Blanchot dentro de uma complicada zona de indistinção.

O silêncio não é o fim, visto que, quando calamos, continuamos a falar incessantemente. Maurice Blanchot calou-se há onze anos, sua morte, no entanto, não representou silêncio ou calar-se de um pensamento que se fazia infinito. Há ainda uma fala silenciosa que possibilita a disseminação do discurso. Esse mesmo silêncio arrebata do vazio uma terceira margem, ele é vertigem que toca o vazio e o faz ecoar. A literatura, dessa forma, deixa de lado a responsabilidade de produzir sentidos fechados, em seu lugar, então, entra uma radicalidade outra que é da ordem da escritura: essa ausência, esse neutro. A falta de Blanchot é da ordem do vazio falante.
22. Ibidem, p. 39.

23. Ibidem, p. 32.

24. BLANCHOT, Maurice. O livro por vir, 2005, p. 321. 


\section{Referências}

AGAMBEN, Giorgio. "Bartleby ou da contingência”.

In: . Bartleby Escrita da potência. Tradução de Manuel

Rodrigues e Pedro. A. H. Paixão. Lisboa: Assírio \& Alvim, 2007.

A potência do pensamento. Tradução de António Guerreiro. Belo Horizonte: Autêntica, 2015.

ARISTÓTELES. Metafísica. Tradução de Edson Bini. São Paulo: Edipro, 2012.

BARTHES, Roland. "A morte do autor". In: . O rumor da língua. Tradução de Mário Laranjeira. São Paulo: Editora Brasiliense, 1988.

"Masculino, feminino, neutro". In: Inéditos vol. 2 - Crítica. Tradução de Ivone Castilho Benedetti. São Paulo: Martins Fontes, 2004.

O neutro: anotaçóes de aulas e seminários ministrados no Collège de France, 1977, 1978. Tradução de Ivone Castilho Benedetti. São Paulo: Martins Fontes, 2003.

Roland Barthes por Roland Barthes. Tradução Leyla Perrone-Moisés. São Paulo: Estação Liberdade, 2003.

BLANCHOT, Maurice. A conversa infinita 3: a ausência do livro, o neutro o fragmentário. Tradução de João Moura Jr. São Paulo: Escuta, 2010.

O livro por vir. Tradução de Leyla Perrone-Moisés. São Paulo: Martins Fontes, 2005.

La escritura del desastre. Tradução de Pierre de Place. Caracas: Monte Avila Editores, 1990.

DELEUZE, Gilles. Crítica e clinica. Tradução de Peter Pál Pebart. São Paulo: Ed. 34, 1997.

MOTTA, Leda Tenório da. Roland Barthes - uma biografia intelectual. São Paulo: Iluminuras/Fapesp, 2011.

ROSA, João Guimarães. "A Terceira margem do rio". In: Primeiras Estórias. Rio de Janeiro: Nova Fronteira, 2001. 